\title{
The LLAMA Brazilian-Argentinian radiotelescope project: progress in Brazil and BRICS collaboration
}

\author{
JACQUES R.D. LÉPINE, ZULEMA ABRAHAM, CARLOS GUILLERMO G. DE CASTRO, \\ JOAQUIM E.R. COSTA, JUAN JOSE LARRARTE, EMILIANO RASZTOCKY, \\ GUILLERMO GANCIO, TANIA DOMINICI, PEDRO P.B. BEAKLINI, FATIMA S. CORRERA, \\ WESLEY BECCARO, MARCOS AURELIO LUQUEZE, ANTONIO VERRI, \\ DANILO CESAR ZANELLA, JACOB KOOI, SJOERD T. TIMMER, DANIELE A. RONSÓ, \\ CARLOS EDUARDO FERMINO \& RICARDO FERNANDO LUIZ
}

\begin{abstract}
We present briefly the LLAMA sub-mm radiotelescope, a joint project of Argentina and Brazil, being mounted in the Andes, Argentina, at $4800 \mathrm{~m}$ altitude. Here we focus on the activities that are going on mostly under the responsibility of Brazil, like the high frequency receivers, parts of the back-end and electronics, the optical system of the telescope to bring the radiation to the receivers, the equipment needed for the integration and verification phase (optical telescope and holography) and the computation system.The main scientific applications that are planned are dscribed. We also report on a joint program with BRICS countries approved in 2019, which will involve the use of LLAMA for testing high-frequency receivers.
\end{abstract}

Key words: LLAMA radiotelescope, sub-mm Astronomy, Argentinian-Brazillian project, Astrochemistry, VLBI.

\section{INTRODUCTION}

LLAMA (Large Latin American Millimetric Array) is a joint Brazilian-Argentinian project of a $12 \mathrm{~m} \mathrm{~mm} / \mathrm{sub}-\mathrm{mm}$ radio telescope, in a site at $4800 \mathrm{~m}$ altitude and $200 \mathrm{~km}$ from ALMA (Atacama Large Millimeter Array), the large interferometer constituted of 66 antennas. The LLAMA antenna has the same type of dish as the ALMA antennas, but will have, in addition to the Cassegrain cabin, two lateral Nasmyth cabins. This will allow to install up to 6 receivers in those cabins. The radiotelescope is similar to APEX (Atacama Pathfinder EXperiment), shown in Figure 1, situated near to ALMA. Another international project, QUBICS (Q\&U Bolometric Interferometer for Cosmology), will be installed close to LLAMA, which will permit to share costs of infrastructure.

The construction of the antenna by VERTEX Antennentechnik GmbH (Germany), started in 2014 and was concluded in 2017. The access road to the site was constructed, as well as a flat area for the observatory. The antenna was transported to Argentina, arriving in 2017 August, but at the present date it is still in containers, at the site of the observatory, waiting for the construction of a concrete foundation on which it will be mounted. A part of the antenna, the Yoke Traverse, which was damaged during the 


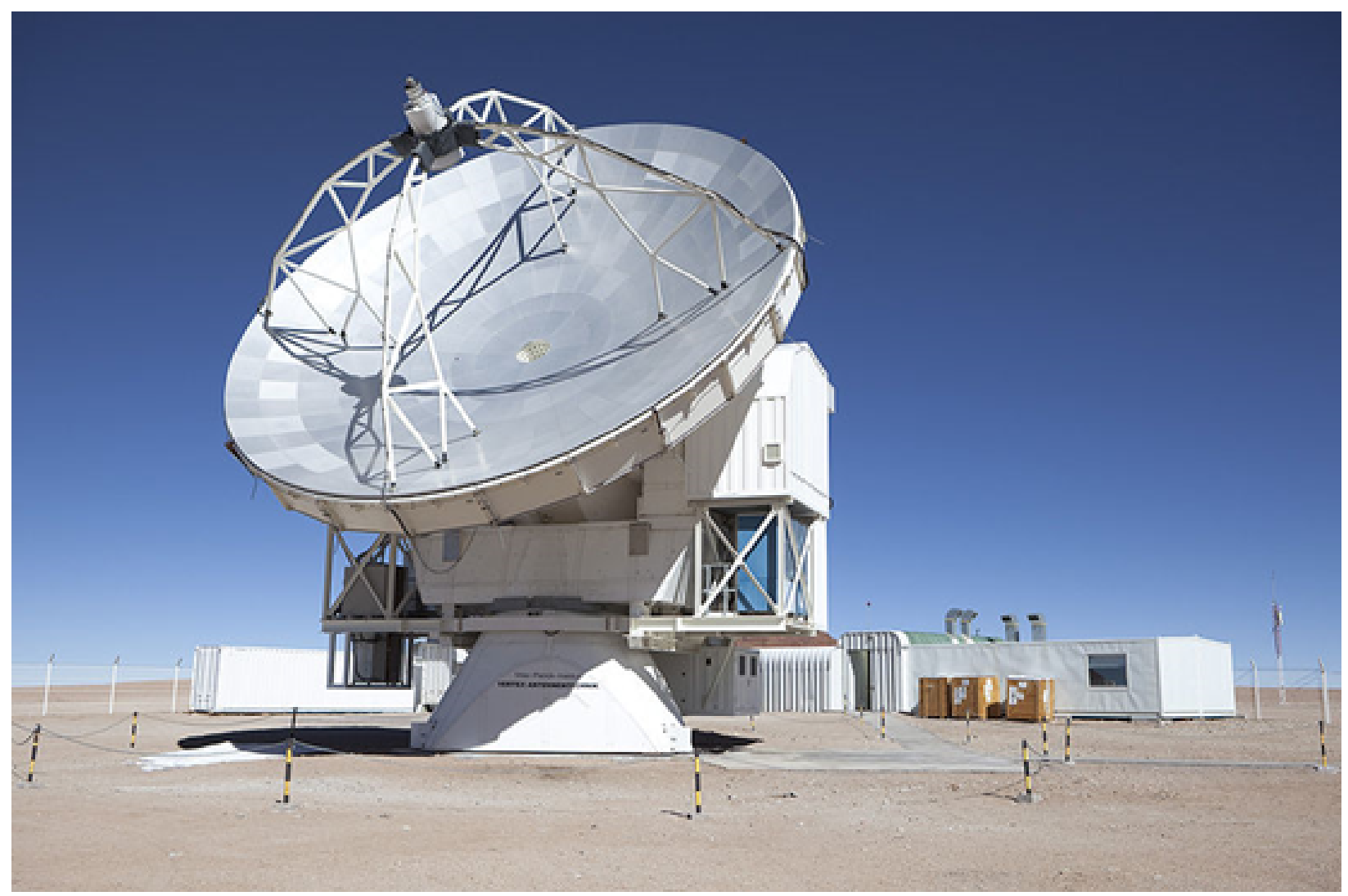

Figure 1. LLAMA will resemble this antenna, APEX, which is situated close to ALMA, and belongs to an European consortium.

transportation in 2017, has been reconstructed and arrived at the observatory in May 2020. (Figure 2).

\section{THE SCIENCE CASE OF LLAMA}

LLAMA will be, for the moment, with APEX, one of the few radiotelescopes operating at Terahertz frequencies ( $\geq 0.1$ Terahertz) in the Southern Hemisphere, including the $10 \mathrm{~m}$ South Pole Telescope. Although the most important radio interferometer of the world, ALMA, is in the Atacama desert in Chile, in the South, ALMA and LLAMA are different and complementary in ways of exploring the Universe. To perform a sucessful observation with ALMA, it is often necessary to prepare the observations with a single dish antenna, when we wish to observe objects that are not seen in the visible. Furtheremore, there are many types of observations that do not need interferometry. And, since LLAMA is situated at $200 \mathrm{~km}$ from ALMA, it will be an ideal partner for VLBI (Very Long Base Interferometry), which will increase the angular resolution of ALMA by a factor 10 in one direction, for special observations. LLAMA will also be naturally inserted in the EHT (Event Horizon Telescope) network of antennas to perform VLBI observations of black holes with very high angular resolution (Doeleman 2010).

The Southern sky is largely unexplored at Terahertz frequencies. Many important and interesting objects are situated in this Hemisphere, like the nearest galaxy, the Magellanic Cloud, and a large part fo the disk of our Galaxy, including the Galactic 


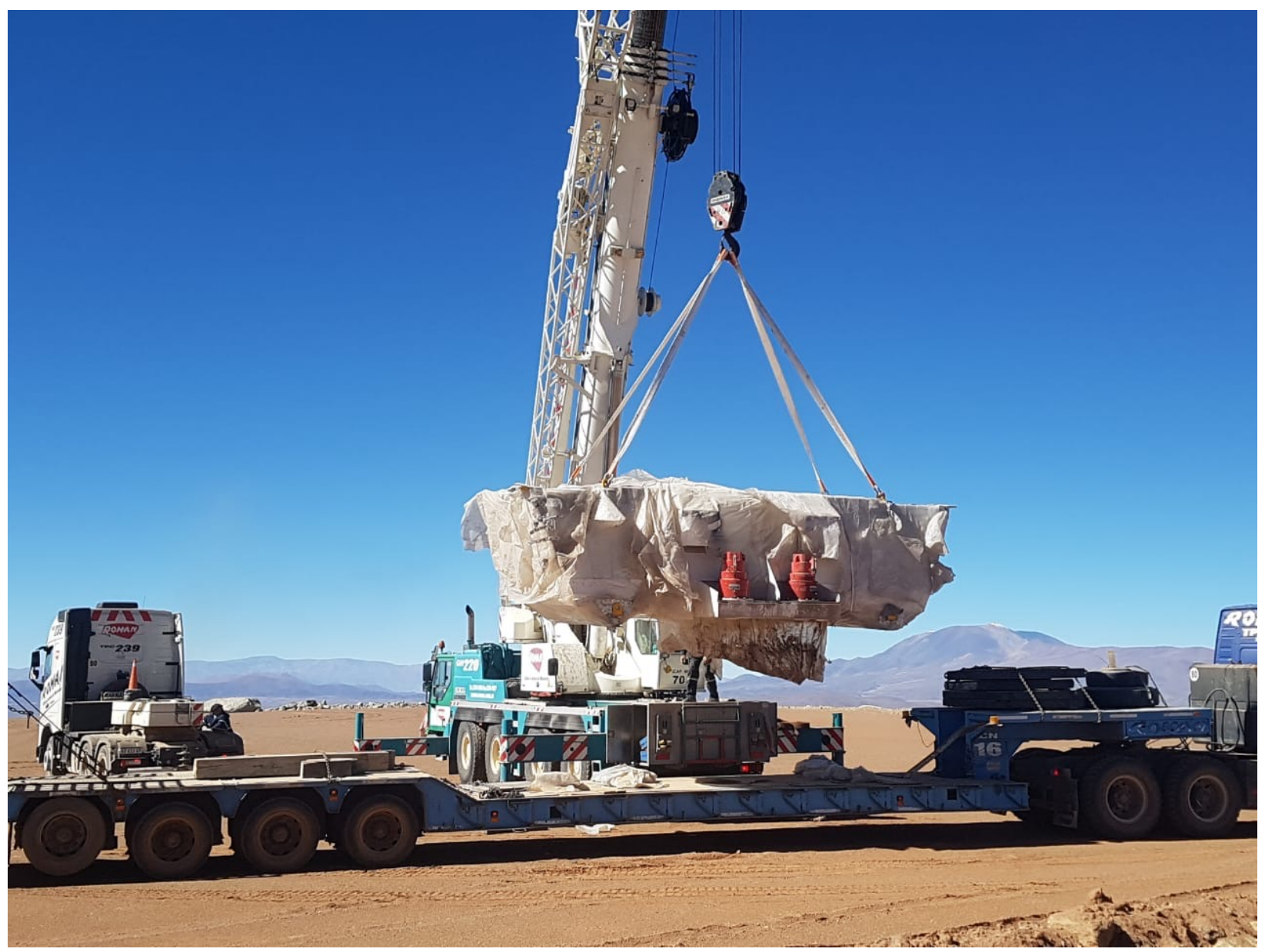

Figure 2. The Yoke Traverse, a piece of the antenna which had to be reconstructed by VERTEX due to an accident, arriving at the site of the observatory.

Center (this region is also observable from the Northern Hemisphere, but in better conditions from the South). There are many groups in Brazil and Argentina willing to observe molecular clouds and star formation regions with LLAMA, in order to better understand the process of star formation. The spectral lines of molecules are exceptional tools to determine the physical conditions of dense regions of the interstellar matter (density, temperature, chemical composition, velocity gradients). Examples of works of this type involving our group are those of Duronea et al. (2019) and Mendoza et al. (2018).
Astrochemistry is a new and active field of reasearch which aims to understand the formation of organic molecules, and to discover new molecular species in the interstellar medium. This research involves theoretical groups that compute the structure of molecules and perform quantum mechanical calculation of the frequencies that should be observable. Other groups perform laboratory experiments simulating the physical conditions of space,to observe the formation or destruction of molecules. Important laboratory groups are located at UFRJ (Dra. Heloisa Boechat) and UNIVAP (Dr. Sergio Pilling). Of course, observations with a radio telescope will be a 
kind of final confirmation of these results. Joint scientific meetings have been organized with the presence of such diversity of research groups like ALLAM2919 (www.allam2919.iag.usp.br) and ISWA (https://www1.univap.br/gaa/iswa/) There are hundreds of well identified molecular lines in the band 5 and band 9 (bands defined in next section) which will be available to LLAMA, but there are also several tens of spectral lines that are clearly molecular, but from molecules that are not yet identified. The list of observed transitions are given, for instance, by Lovas et al., 1985 (frequently updated).

Astrochemistry will be an important tool in the searh for life. It is technically impossible at the moment to observe the chemical composition of an exoplanet, but we could have indirect evidence of it because the chemical composition of objects of a protoplanetary disk seems to be related to that of the interstellar cloud from which the star originated (Lefloch et al. 2018).

There are many lines of research in Extragalactic Astronomy. Observations of red-shifted CO can be used for star formation rate studies at an earlier epoch. For instance, the star-formation history of the Universe could be investigated by observing the protogalaxies of the first billion years of the universe. $\mathrm{H}_{2} \mathrm{O}$ masers from distant galaxies could be part of a project to get mesurements of their distances and to estimate the Hubble constant in an independent way (Braatz 2009).

A group of researchers intends to observe quasars, blazars and nuclei of Seyfert galaxies and investigate their variabilities (eg. Beaklini et al. 2019). These objects are high luminosity AGNs (Active Galactic Nuclei) that are also bright at radio wavelength. Some of them, VVOs (Violent Variable Objects) and BL Lacs objects, show an intense variability at all wavelengths at which they are observed: radio, infrared, optical, UV,
$X$-ray and $\gamma$-ray. In the submillimeter range, the monitoring campaigns are rare; LLAMA will provide crucial information to understand the physical processes occurring in these sources (Stevens et al. 1998).

Another field of research will be solar astronomy. The antenna is specially designed to be able to point towards the Sun, because the visible and infrared energy will be scattered by the de-polished surface of the dish and will not concentrate on the secondary reflector, which would damage it. This surface treatment is not typical in $\mathrm{mm}$ radio telescopes. Furthermore, in a latter stage, a dichroic mirror will be installed in the optical system, which will permit to observe with two receivers simultaneously (one in each Nasmyth cabin). This will allow to determine phase differences of Solar burst-like peaks at different frequencies and spectral hardness of the particles acceleration. Mapping the full disk in total power is extremely valuable for the analysis of the chromosphere temperature structure (Brajša et al. 2018) Fast mapping of active regions during transient emission will contribute to the comprehension of the energy transport at lower atmosphere levels.

The plan for the use of the telescope is to have the observation time allocated by a committee, that will judge and set priorities to the proposals sent by the community. A few time consuming surveys supported by a larger number of astronomers than the usual proposals could be adopted. The Argentinian partners are planning to install a bolometer for research in Cosmology in LLAMA, in association with QUBICS.

\section{HIGH FREQUENCY RECEIVERS AND BACK-END}

At the very beginning LLAMA will operate with 2 heterodyne receivers, in Band $5(162-211 \mathrm{GHz})$ and Band 9 (602-720 GHz) (ALMA bands). Other 
receivers, Band 2+3 (67-116 GHz) and band 6 (211-275 GHz), are planned. These last two are important because they are the ones used in VLBI experiments by other radiotelescopes. For the moment we have not yet taken a decision to fill the available room for 2 additional receivers. This will depend on the needs of the community and the opportunities to get them at low cost.

The two initial receivers are ALMA-like cartridges (Figure 3), cooled receivers. At present we have only one cryostat with room for 3 cartridges, constructed by NAOJ (Tokyo, Japan). We obtained significant contribution from NOVA-Groningen Lab (Holland) for the construction and tests of the receivers, band 9 being constructed by NOVA and band 5 by GARD (Gothenburg, Sweden), and donated to LLAMA by the European Southern Observatory. The tests performed at NOVA trained 2 Brazilians and 1 Argentinian engineers to measure and adjust all the parameters of the receivers, like the system temperature, bandwidth, stability. A prototype IF processor has been constructed and tested at NOVA and could be used in principle for first light. It has a Total Power output for observations of continuum sources, and is able to feed a Fast Fourier Transform spectrometer for line observations. However, the prototype IF processor has a limited bandwidth $(2.5 \mathrm{GHz})$, compared to the possibilies of the FFT spectrometer, already purchased by the Argentinean partners, that can process an instantaneous bandwidth of $16 \mathrm{GHz}$. We started the work of constructing new IF processors at the Engineering School of University of São Paulo (hereafter Escola Politécnica), duplicating the bandwidth, and allowing the simultaneous observation of the two polarizations. The same spectrometer will be used with all the front-end receivers, by switching the receiver and perfoming the needed down convertion of frequencies.

\section{NACOS - NASMYTH CABIN OPTICAL SYSTEM}

The whole "optical" system, named NACOS, includes mirrors to bring the beam to the cryostat where the receivers will be installed, and mechanical parts to hold the mirrors and the cryostat (Figure 4).

NACOS contains 4 remotely controlled mirrors plus 6 not controlled (8 flat and 2 curved ones). The mirrors in the Cassegrain cabin allow to choose to which Nasmyth cabin the signal will be sent. Then, inside a Nasmyth cabin, the mirrors permit to select the receiver to be used, among 3 receivers that can be installed in the cryostat. NACOS also serves to support the cryostat, in the Nasmyth cabin, and lift it for maintenance of the cold He head. At first light we will use only one of the two Nasmyth cabins. NACOS also supports a system of calibration loads, in the Cassegrain cabin, with 2 temperature-controlled blackbody loads. The NACOS mechanical structures have been built by ALFA Ferramentaria in Araraquara, São Paulo State (Figure 5). It is ready and in a phase of alignment and tests.

\section{SUBSYSTEMS FOR ANTENNA AIV PROCESS}

The Assembly, Integration and Verification phase (AIV) of the antenna will be focussed on veryfying the antenna control, antenna motion and overall antenna structure. At this phase tests are run to confirm the reliable control of the motion of the antenna. An optical telescope system (OPTS) will be used for inicial tests and setting of parameters of the pointing model. OPTS is composed by a refractor optical telescope with carbon fiber tube that will be mounted in a hole of the antenna dish, with an additional protection tube and remote shutter control. The telescope is equipped with a camera that will take otical images of the field of astrometric 


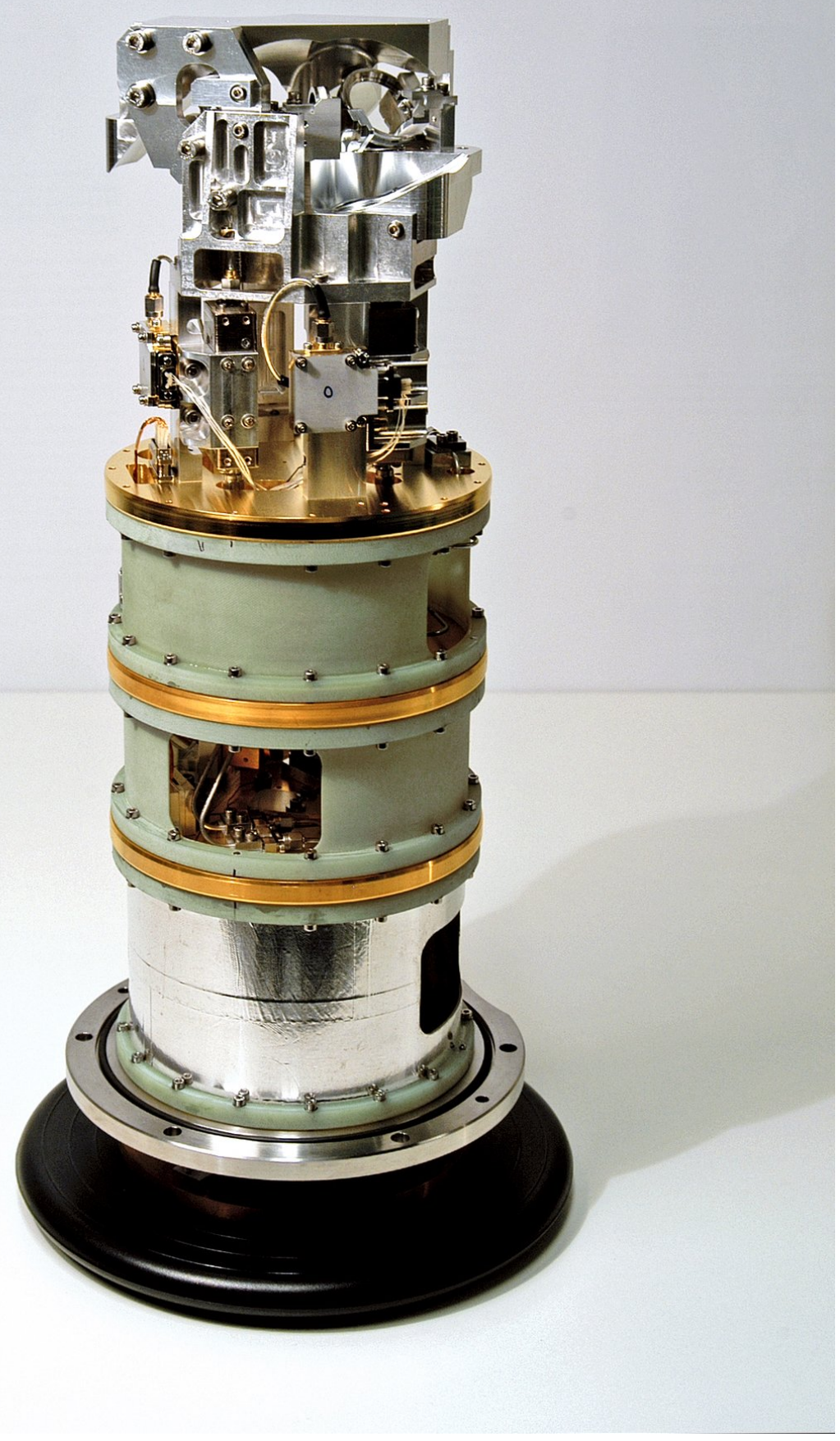

Figure 3. The band 9 cartridge mounted receiver, ready to be introduced in the cryostat.The cartridge has three cold stages that operate in vacuum at temperatures of $4 \mathrm{~K}, 20 \mathrm{~K}$ and $90 \mathrm{~K}$, and room temperature, from top to bottom. The superconducting mixer, which down-converts the signal from the sky with a stable wave produced in a Local Oscillator to generate an Intermediate Frequency signal, is in the $4 \mathrm{~K}$ stage at the top. 


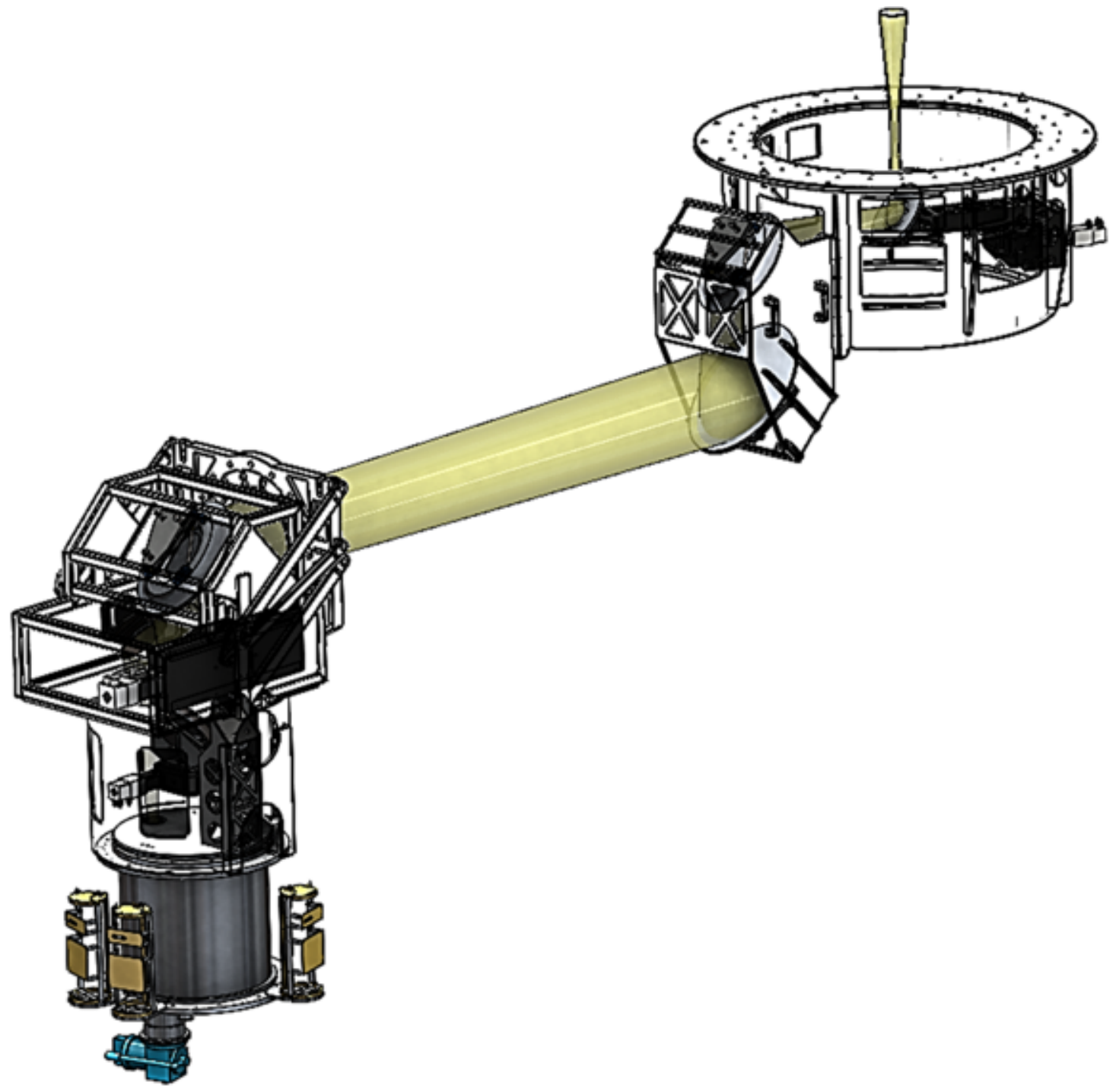

Figure 4. Schematic presentation of the NACOS system. On the right, the CAS system, that goes in the Cassegrain Cabin, just below the dish. The beam, in yellow, can be sent to one Nasmyth cabin or to the other. Here only one of the two NAS systems is presented, on the left side of the figure; it holds a cryostat containing cooled receivers.

stars, to detect the pointing errors. The OPTS sofware will measure automatically the offset of the objects from the center of the image field.

For the alignment of the panels of the dish, near field holography will be used (Baars 2007, López-Pérez 2014). The holographic system is composed of two separate parts, the receiver and the transmitter. The holography receiver will be on loan from NRAO (National Radio Astronomy Observatory, USA) and ALMA. This part of the equipment will be installed on the antenna, near its prime focus, during the measurement campaigns. The holography tranmitter will be mounted on a tower situated at a distance 300 $\mathrm{m}$ from the radiotelescope. The principle is to detect differences in phase between the signal coming directly from the transmitter and the signal coming from the transmitter but entering in the receiver after a reflection by the antenna dish. The holography system will produce maps 


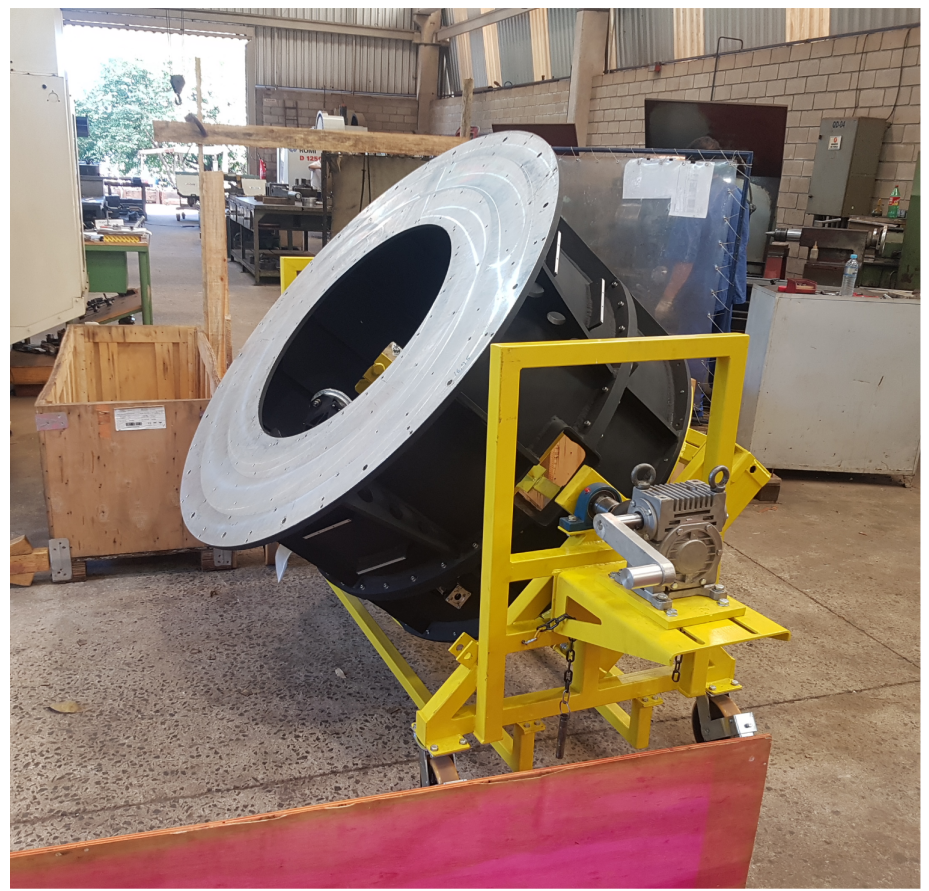

(a)

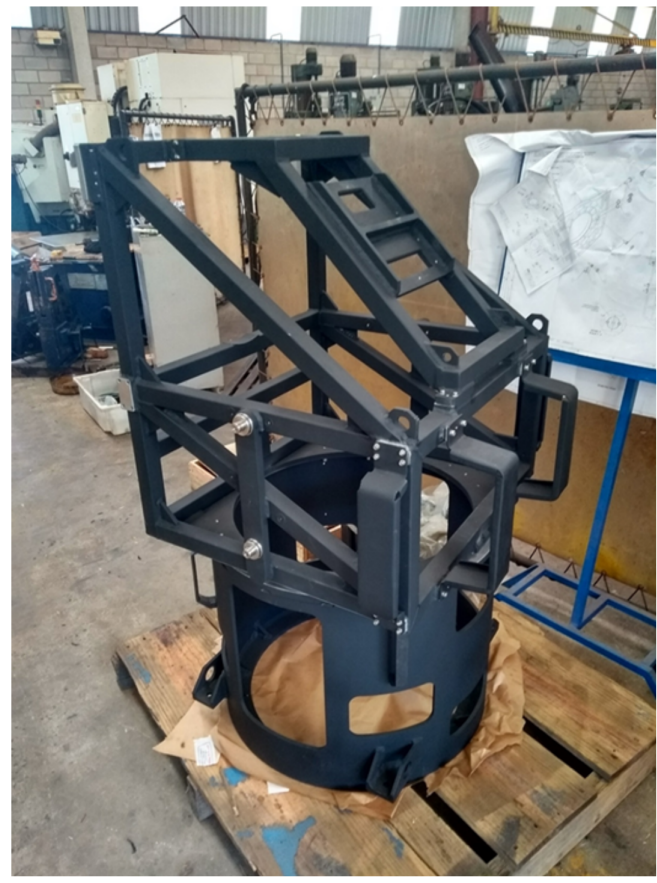

(b)

Figure 5. The NACOS system, in the Alfa factory at Araraquara.

of the surface errors of the radiotelescope dish, that will be corrected by adjusting the position of the panels. The goal is to reach a surface rms accuracy of $20 \mu \mathrm{m}$. The transmitter, working at $104 \mathrm{GHz}$, is being developped in Brazil at Escola Politécnica.

\section{SOFTWARE DEVELOPPMENT}

The LLAMA software is a major challenge, since the antenna will be operated remotely. The software controls the motion of the dish, the receivers (high frequency and IF), the spectrometer, calibration system, data acquisition, quick view of the results, data storage, monitoring of sensors, and more. We are using the ACS program infrastructure of ALMA for integration and specific local softwares for many instruments. This work is being developped in
São Paulo (IAG-USP, with contributions from Mackenzie University and INPE/MCTI).

\section{THE BRICS COLLABORATION}

A new opportunity of international collaboration became available in 2019, by means of a call for proposals in the BRICS countries. We started the establishment of a collaboration between Brazil, Russia, South Africa and China to develop the technology for the construction of very high frequency receivers (sub-Terahertz). It is a case with a well defined plan, under the leadership of Dr. Valery Koshelets (Kotel'nikov Institute of Radio Engineering and Electronics, Russia) and with the participations of Dr. Huabing Wang (School of Electronic Science and Engineering, Nanjing University, China) and of Dr. Coenrad Fourie (Stellenbosch University, Department EE Engineering, South 
Africa). We are already developping SIS (Superconductor-Insulator-superconductor) devices in Russia, to be used as mixers of high frequency receivers (about $250 \mathrm{GHz}$ ) of high quality, which will be complemented with IF (Intermediate Frequency) processor constituted by a parametric Josephson travelling-wave amplifier with bandwidth 2 to $12 \mathrm{GHz}$, designed in South Africa. This program will also include a collaboration of the NOVA labs in Groningen (Holland, not a BRICS member), under the responsibility of Dr. Andrey Baryshev. In Nova the SIS are being tested, to be later installed inside the mixer of a sub-mm receiver (Band 6). The main role of Brasil will be to participate in these tests and provide a suitable high altitude radiotelescope (LLAMA) to test the receivers. At present we have a PhD student (Daniele Ronsó) in double-titulation program between USP and University of Groningen, working with Dr. Andrey Barischev on the tests of SIS devices made in Russia for the development of a band 6 receiver for LLAMA. All the involved countries have funds approved in their own country. The development in China will be in close collaboration with South Africa, on IF processors. The precise role of Brazil in this part of the project is still to be defined.

This BRICS activity will result in an important contribution to Terahertz technology transfer to Brazil by the LLAMA project.

\section{Acknowledgments}

This work is supported by FAPESP grant 2011/51676-9, and in Argentina by Ministry of Science and Technology. We are gratefull to: Dr. Thijs de Graauw who spendt much time to support the project as a general adviser, Juan Pablo Garcia for his competent work as a project engineer, César Strauss and Fernando Hauscarriaga for software development and Jose Eduardo Silva for the perfect polishment of the flat mirrors of the NACOS system.

\section{REFERENCES}

BAARS JWM, LUCAS R, MANGUM JG \& LOPEZ-PEREZ JA. 2007. Near-Field Radio Holography of Large Reflector Antennas. IEEE Antennas and Propagation Magazine 49: 24. doi:10.1109/MAP.2007.4395293.

BEAKLINI PPB, DOMINICI TP, ABRAHAM Z \& MOTTER JC. 2019. Multiwavelength analysis of brightness variations of $3 C$ 279: probing the relativistic jet structure and its evolution. A\&A 626: A78. doi:10.1051/0004-6361/201935170.

BRAATZ JA, CONDON JJ, HENKEL C, LO KY \& REID MJ. 2009. Cosmology with Water-vapor Megamasers. In: astro2010: The Astronomy and Astrophysics Decadal Survey. vol. 2010. p. 23.

BRAJSA R ET AL. 2018. Observations of the solar chromosphere with ALMA and comparison with theoretical models. In: 20th Cambridge Workshop on Cool Stars, Stellar Systems and the Sun. Cambridge Workshop on Cool Stars, Stellar Systems, and the Sun. p. 37. doi:10.5281/zenodo.1462863.

DOELEMAN S ET AL. 2009. Imaging an Event Horizon: submm-VLBI of a Super Massive Black Hole. In: astro2010: The Astronomy and Astrophysics Decadal Survey. vol. 2010. p. 68.

DURONEA NU ET AL. 2019. Cyanoacetylene in the outflow/ hot molecular core G331.512-0.103. MNRAS 489(2): 1519-1532. doi:10.1093/mnras/stz2087.

LEFLOCH B ET AL. 2018. Astrochemical evolution along star formation: overview of the IRAM Large Program ASAI. MNRAS 477(4): 4792-4809. doi:10.1093/mnras/sty937.

LOPEZ-PEREZ JA, DE VICENTE ABAD P, LOPEZ-FERNANDEZ JA, TERCERO MARTINEZ F, BARCIA CANCIO A \& GALOCHA IRAGUEN B. 2014. Surface Accuracy Improvement of the Yebes 40 Meter Radiotelescope Using Microwave Holography. IEEE Transactions on Antennas and Propagation 62(5): 2624-2633. doi:10.1109/TAP.2014.2307351.

LOVAS FJ. 1986. Recommended Rest Frequencies for Observed Interstellar Molecular Microwave Transitions-1985 Revision. Journal of Physical and Chemical Reference Data 15(1): 251-303. doi:10.1063/1.555771.

MENDOZA E, BRONFMAN L, DURONEA NU, LÉPINE JRD, FINGER R, MERELLO M, HERVIAS-CAIMAPO C, GAMA DRG, REYES N \& ̊̊KE-NYMAN L. 2018. G331.512-0.103: An Interstellar Laboratory for Molecular Synthesis. I. The Ortho-to-para Ratios for $\mathrm{CH}_{3} \mathrm{OH}$ and $\mathrm{CH}_{3} \mathrm{CN}$. ApJ 853(2): 152. doi:10.3847/1538-4357/aaa1ec. 
STEVENS JA, ROBSON EI, GEAR WK, CAWTHORNE TV, ALLER MF, ALLER HD, TERÄSRANTA H \& WRIGHT MCH. 1998. Variability of the Centimeter-Submillimeter Spectrum and Polarization of 3C 273 during Outburst. ApJ 502(1): 182-191. doi:10.1086/305883.

\section{How to cite}

LEPINE JRD ET AL. 2021. The LLAMA Brazilian-Argentinian radiotelescope project: progress in Brazil and BRICS collaboration. An Acad Bras Cienc 93: e2O2O0846. DOI 10.1590/o001-3765202120200846.

Manuscript received on June 1,2020;

accepted for publication on August 6, 2020

\section{JACQUES R.D. LÉPINE ${ }^{1}$}

https://orcid.org/0000-0002-8969-0313

\section{ZULEMA ABRAHAM ${ }^{1}$}

https://orcid.org/0000-0003-0012-1315

\section{CARLOS GUILLERMO G. DE CASTRO ${ }^{2}$}

https://orcid.org/0000-0002-8979-3582

JOAQUIM E.R. COSTA 3

https://orcid.org/0000-0002-0703-4735

\section{JUAN JOSE LARRARTE 4}

https://orcid.org/0000-0003-3281-8782

\section{EMILIANO RASZTOCKY}

https://orcid.org/0000-0002-1984-7821

GUILLERMO GANCIO 4

https://orcid.org/0000-0003-1282-3031

\section{TANIA DOMINICI}

https://orcid.org/0000-0002-1522-0925

PEDRO P.B. BEAKLINI ${ }^{1,6}$

https://orcid.org/0000-0001-5071-1343

FATIMA S. CORRERA7

https://orcid.org/0000-0001-7826-088X

\section{WESLEY BECCARO 7}

https://orcid.org/0000-0001-6599-2344

MARCOS AURELIO LUQUEZE7

https://orcid.org/0000-0002-5835-4069

\section{ANTONIO VERRI ${ }^{7}$}

https://orcid.org/0000-0003-2956-3408

DANILO CESAR ZANELLA ${ }^{1}$

https://orcid.org/0000-0003-0343-9062

JACOB KOOI ${ }^{8}$

https:// orcid.org/0000-0002-6610-0384

SJOERD T. TIMMER ${ }^{9}$

https://orcid.org/0000-0003-0223-9368
DANIELE A. RONSÓ ${ }^{1}$

https://orcid.org/0000-0002-9731-166X

\section{CARLOS EDUARDO FERMINO ${ }^{10}$}

https://orcid.org/0000-0001-5214-0791

RICARDO FERNANDO LUIZ ${ }^{11}$

https://orcid.org/0000-0001-9178-109X

${ }^{1}$ Universidade de São Paulo, IAG, Rua do Matão, 1226, Cidade Universitária, 05508-090 São Paulo, SP, Brazil

${ }^{2}$ Universidade Presbiteriana Mackenzie, Rua da Consolação, 930, Consolação, 01302-907 São Paulo, SP, Brazil

3 Instituto Nacional de Pesquisas Espaciais, DAS/INPE/MCTI, Av. dos Astronautas, 1.758, Jardim da Granja, 12227-010 São José dos Campos, SP, Brazil

4Instituto Argentino de Radioastronomía, Camino Gral. Belgrano Km 40 (Parque Pereyra Iraola), Berazategui, Prov. de Buenos Aires, Argentina

${ }^{5}$ Museu de Astronomia e Ciências Afins, Ministério da Ciência, Tecnologia e Inovações (MAST/MCTI), Rua General Bruce, 586, São Cristóvão, 20921-030 Rio de Janeiro, RJ, Brazil

${ }^{6}$ National Radio Astronomy Observatory, 1003 Lopezville Road, Socorro, NM 87801, U.S.A.

7 Universidade de São Paulo, Escola Politécnica, Av. Prof. Luciano Gualberto, trv. 3, no 158, 05508-010 São Paulo, SP, Brazil

${ }^{8}$ California Institute of Technology, 1200 E California Blvd. MC 155-44, Pasadena, CA 91125, U.S.A.

${ }^{9}$ Department of Astrophysics/IMAPP, Heyendaalseweg 135, Radboud University, Nijmegen, Netherlands

${ }^{10} \mathrm{eFe}$ Tecnologia, Av. Jorge Fernandes de Mattos, 311, Distrito Industrial VIII, 14808-162 Araraquara, SP, Brazil

${ }^{11}$ Alfa Ferramentaria, Av. Brandina Saavedra Campani 441, Bairro Dist Industrial III, 14806-613 Araraquara, SP, Brazil

Correspondence to: Jacques Raymond Daniel Lépine

E-mail: jacques.lepine@iag.usp.br

\section{Author contributions}

JRD Lepine and Z Abraham were PIs of the FAPESP LLAMA Project, GG Castro responsible for the software development,and D.Zanella the main software developper, JER Costa preparation of Solar LLAMA Science, JJ Larrarte management and electronic development, E. Rasztocky tests and laser alignement of NACOS, G.Gancio development of $\mathrm{Fl}$ system and down-converter, T. Dominici management and responsible for optical telescope project, PP. Beaklini preparation of Holography measurements and LLAMA Science, FS Correra and W Beccaro, responsible for development of Holography project, $\mathrm{M}$ Luqueze and S Verri measurements of cooled receiver characteristics and mounting of prototype $\mathrm{Fl}$ system in Leiden, J Kooi design of mm-wave "optical" system, ST Timmer software development, DA Ronsó designed, supervised construction and characterization of the 
horn of the Holografic transmitter, CE Fermino supervised the construction of NACOS system and of the control systems of the mirrors and calibration loads of NACOS, FL Ricardo, owner of the Alfa Ferramentaria, took the decisions on fabrication process of each mechanical component of NACOS.

(cc) BY 
An Acad Bras Cienc (2021) 93(Suppl. 1): e20200846e DOI 10.1590/0001-3765202120200846e Anais da Academia Brasileira de Ciências | Annals of the Brazilian Academy of Sciences

Printed ISSN 0001-3765 I Online ISSN 1678-2690

www.scielo.br/aabc | www.fb.com/aabcjournal

\section{ERRATUM}

In the article The LLAMA Brazilian-Argentinian radiotelescope project: progress in Brazil and BRICS collaboration, with DOI number: $\quad$ https://doi.org/10.1590/0001-3765202120200846, published in the journal Anais da Academia Brasileira de Ciências, 93(Suppl. 1): e20200846.

Page 1

Reads:

TANIA DOMICINI

Should read:

TANIA DOMINICI

\section{Reads:}

WESLEY BECCARI

Should read:

WESLEY BECCARO

Page 10

\section{Reads:}

TANIA DOMICINI

Should read:

TANIA DOMINICI

\section{Reads:}

WESLEY BECCARI

Should read:

WESLEY BECCARO

(cc) BY 